\title{
La batalla entre consumismo y el medio ambiente. Una responsabilidad de todos
}

The battle between consumerism and environment.

Everyone's responsibility

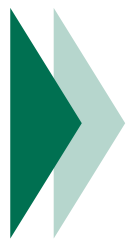

Ricardo Prada Ospina

PhD en Ciencias Empresariales por la Universidad Antonio de Nebrija, España. Doctor en Gestión por la Universidad EAN, Colombia; MBA-magíster en Administración; especialista en Ingeniería de Producción; ingeniero mecánico y consultor empresarial.

E-mail: rpradao@universidadean.edu.co

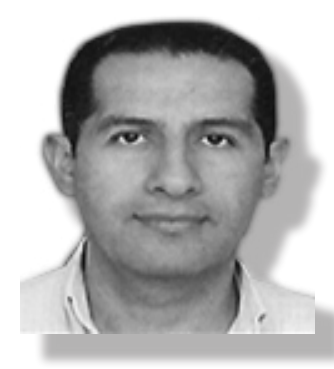

Pablo C. Ocampo

Doctorando en Gestión Estratégica y Negocios Internacionales, Universidad de Sevilla, España. Master in Management of Logistics Systems Ecole Polytechnique Federal de Lausanne Switzerland.

E-mail: pabloc.ocampo@universidadean.edu.co - pablo4610@yahoo.com

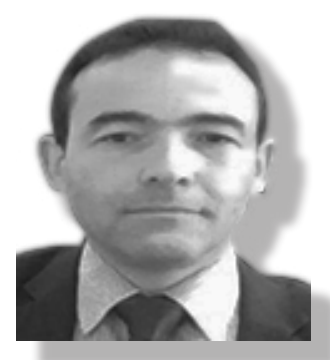




\section{RESUMEN}

Cada vez nos vemos enfrentados a consumir múltiples productos y servicios, sin tener en cuenta el perjuicio que se tiene al no tener claridad de las máximas fundamentales que se deben de tener en cuenta para no generar mayor contaminación al planeta. Una de las teorías que va tomando fuerza es el Sustainability Supply Chain Management, $S S C O$, que, configurado con los procesos de la gerencia de la cadena de abastecimiento verde, coadyuvan a reducir el impacto al medio ambiente y a mejorar los acuerdos de nivel de servicio de las organizaciones.

Palabras Clave: Sustentabilidad, Green Supply Chain Management, consumismo, medio ambiente.

\section{Abstract}

Every time we are confronted with consuming multiple products and services, regardless of the damage that has clearly not having the fundamental maxims that must be taken into account to avoid creating more pollution to the planet. One theory that has gained momentum is the Sustainability Supply Chain Management, SSCO, which configured with processes management chain green supply, contribute to reducing the environmental impact and improve servicelevel agreement of organizations.

Keywords: Sustainability, Green Supply Chain Management, consumerism, environment.

\section{Introducción}

El mundo contemporáneo no despierta aún del letargo e indiferencia para con el manejo del medio ambiente, la problemática de erosión y contaminación presente en el planeta va a conllevar que las nuevas generaciones tengan condiciones de vida muy complejas, si desde ya no hacemos algo.

Uno de las afecciones más críticas es el inadecuado y voraz concepto que tenemos del consumo de bienes y productos. Hoy, es muy difícil pensar en transitar en la cotidianeidad sin vernos abocados a compartir espacio con materiales provenientes de residuos fósiles, como el plástico.

Este artículo, nos presenta un enfoque práctico de modificación del pensamiento desde el punto de vista de los consumidores y clientes que somos, como alternativa de cambio de las actuales prácticas manufactureras.

Las cadenas de abastecimiento deben fortalecer la cultura organizacional, con base en la teoría de orientación de la gerencia de la cadena abastecimiento sostenible o Sustainability Supply Chain Orientation, $S S C O$, debido a que es necesario crear mayor conciencia a los líderes empresariales y a los grupos de interés que se preocupen por la mejora del desempeño logístico, mediante la aplicación de conceptos como la orientación a la sostenibilidad y a la orientación a la gerencia de la cadena de abastecimiento, que velan porque que la parte interna de la red tal como las empresas individuales o focales se preparen para una estrategia integradora entre proveedores y clientes (Signori, Flint \& Golicic, 2015).

Muchos líderes empresariales ven como un gasto innecesario aplicar filosofías enmarcadas a la logística verde o de logística de reversa dentro de sus empresas, lo cual es 
necesario madurar a otros conceptos como de valor agregado en las redes de valor

\section{Contradicción y consumo}

- Tal parece que hoy en día se vive en una aparente contradicción: por un lado, cuando se pregunta indistintamente cuánto está afectando la problemática actual del medio ambiente, seguramente no habrá duda en responder que muy poco o nada, puesto que se asume que ese es un problema de otros, para otras zonas o sitios distintos a la ciudad o región donde se habita y por tanto, no hay compromiso con el tema; pero por otra parte, si nos colocaran, cerca de la vivienda, un ruidoso transformador o una gigantesca antena, o si dejasen de recoger la basura en el vecindario por unos pocos días, la molestia y mortificación serían enormes.

- Así mismo, solemos solidarizarnos temporalmente con el medio ambiente, cuando en los medios aparecen noticias de desastres ecológicos, como el reciente desembarque carbonífero en cercanías de la bahía de Santa Marta, hechos de los que prontamente nos olvidamos, para luego observar, como algo común y casi normal, a alguien depositar tranquila e indiscriminadamente en la basura, las pilas, las baterías y otros desperdicios tóxicos, mezclados y sin discriminar, junto con residuos orgánicos.

También se observa que no contamos con una verdadera logística de reversa para los tarros o depósitos ya utilizados de los insecticidas, lo cual estos productos ya utilizados o desechados llegan al botadero de basura y contaminan las aguas subterráneas o el suelo, generando un problema aún más grave como la contaminación de fuentes hídricas.
- Ni qué decir de la práctica frecuente de arrojar a la calle papeles, colillas y cáscaras desde la ventana de los vehículos en marcha, o simplemente al caminar y consumir un alimento en forma despreocupada. ¿Cuál puede ser la razón de ese egoísmo ambiental que nos rodea y que sólo esporádicamente nos sensibiliza con el medio ambiente? La razón podría estar en la transformación del ciudadano, de una etapa previa de indiferencia social cotidiana hasta otra de absoluto atrapamiento por el consumismo desenfrenado.

- Somos responsables de la avalancha de productos y empaques no amigables que inundan los mercados, al aceptar su fabricación y distribución cuando los compramos, usamos y consumimos, sin reproche ni protesta alguna. El empresario de esa manera encuentra en nuestro silencio y poca respuesta, su mejor aliado, para seguir adelante con su exitosa manufactura.

- Como consumidores que somos, podemos con nuestras decisiones y acciones contribuir favorablemente a disminuir las excesivas cargas diarias de desechos, con limitada capacidad para ser absorbidos por medio, cuando decididamente optemos por rechazar toda práctica inadecuada. Convertir los actuales procesos fabriles en manufacturas más amigables con el medio ambiente, o que las empresas en general adopten un mayor compromiso con sus prácticas y operaciones en pro de la sociedad, son acciones que nosotros como clientes podríamos obligar si así lo decidiéramos, a la hora de demandar sus productos o servicios. Es pues el consumo masivo y desproporcionado, la razón recurrente para que los industriales sigan cosechando triunfos y amasando mucho dinero, pero en detrimento del medio ambiente. 


\section{La declaración de Rio que nadie escucha}

La conferencia de las Naciones sobre el Medio ambiente y el Desarrollo se reunió en Rio de Janeiro del 3 al 14 de junio de 1992, reafirmando la declaración de la conferencia de las Naciones Unidas sobre el Medio humano, aprobada en Estocolmo el 16 de junio de 1972, es decir, hace más de 40 años.

Esta declaración trató de establecer una alianza mundial, nueva y equitativa, mediante la creación de nuevos niveles de cooperación entre los estados productores y consumidores, los sectores claves de la sociedad y en general, con las personas, en la búsqueda de alcanzar acuerdos internacionales en los que se respeten los intereses de todos y se proteja la integridad del sistema ambiental y de desarrollo mundial. El objetivo fundamental fue reconocer la naturaleza integral e interdependiente de la Tierra, nuestro hogar.

Infortunadamente, este compromiso de aplicarla "Declaración de Rio"sobreunadecuado desarrollo sostenible, ni se ha establecido ni ha penetrado en las sociedades como debiera ser, y con su ausencia, indirectamente ha posibilitado que los empresarios, sobre todo en los países del tercer mundo, le resten importancia y continúen desarrollando prácticas de manufactura cada vez menos ambientalistas.

El progreso industrial al que se ha llegado, ha sido el resultado de múltiples aportes e investigaciones que han llevado al perfeccionamiento en los bienes elaborados. Indudablemente, una serie de productos se han desarrollado con nuevas técnicas de transformación, brindando calidad y seguridad para el usuario final. Nuevas tendencias en los procesos fabriles que contribuyen al desarrollo y satisfacción de las necesidades del ser humano, así como, técnicas que se inclinan a la productividad y competitividad de las organizaciones son requeridas hoy para el desarrollo de nuevos productos.

\section{Innovación}

La innovación y su desarrollo deben nacer de ideas que conduzcan a mejorar la calidad de vida del ser humano. Los procesos, como verdaderos motores de la manufactura, están inmersos en los conceptos modernos de innovación y desarrollo que involucran cada vez, nuevas tendencias de fabricación.

No obstante, si bien es cierto que las organizaciones están abocadas a innovar sus procesos en la búsqueda de una mayor y mejor eficiencia en el manejo de los recursos que poseen, también lo es, la necesidad de desarrollar nuevas rutas de manufactura en las organizaciones, debido a los embates de la globalización e internacionalización que enfrentan, pero por otro lado, estas innovaciones, por ende, no sólo se deben ver reflejadas en sus procesos sino también en los diseños innovadores de los productos, promoviendo con ello que, así como lo estipula la declaración de Rio, los consumidores modifiquen su comportamiento, adquiriendo con preferencia los productos de industrias amigables con el ambiente y la sociedad.

El desarrollo en dichos procesos fabriles con nuevas tecnologías de manufactura empieza a surgir de una forma sostenible, de tal forma que el usuario final de los productos transformados empieza a evidenciar estos cambios. La visión de las operaciones de manufactura futura seguramente estará enmarcada en la innovación y desarrollo de mejores formas de elaborar y tratar los materiales, enfocados al bienestar y satisfacción de los seres humanos. En consonancia con ello, la responsabilidad del cliente a la hora de consumir, debería propiciar cambios sociales positivos y de mayor impacto. Hoy, el mundo padece la falta de compromiso 
y solidaridad con el planeta, y el desarrollo industrial está abocado al consumo de prácticas y materiales que erosionan cada vez más la vida misma.

Los derivados del petróleo no escapan a ello: muchos de los plásticos que se utilizan en la industria y también en nuestra vida cotidiana, son productos que tienen una pobre y muy limitada capacidad de autodestruirse y esto acarrea grandes consecuencias, las cuales quedan marcadas durante muchos años en el medio ambiente creando residuos que lo infertilizan. Mientras más se avance en la desproporcionada utilización del plástico, como elemento importante del diario vivir de la sociedad, más estaremos contribuyendo con gran velocidad a impactar negativamente las tierras y los recursos en general.

\section{El consumo sostenible}

Consumir en forma sostenible es el camino. El consumo sostenible consisteen utilizar menos recursos y provocar menos contaminación para satisfacer las diferentes necesidades de la gente con mejores resultados ambientales y sociales, además de estimular a los proveedores a ser innovadores, a que mejoren la competencia y promuevan el desarrollo y el crecimiento económico.

En el pasado, varias empresas se han visto en la obligación de aplicar políticas sostenibles incluso con sus proveedores: La presión de un conglomerado de universidades de Estados Unidos que amenazó con dejar de seguir adquiriéndoles sus implementos deportivos para dotar a sus equipos universitarios, empujó a Nike, la todopoderosa compañía mundial de artículos deportivos, a crear un fondo de más de $\$ 1,5$ millones de dólares para que dos empresas proveedoras suyas, instaladas en Honduras, hicieran frente al pago de cargas sociales a sus empleados.
Otras han sido más osadas en preservar el medio ambiente, como lo fue en España la cadena de supermercados francesa Carrefour, la cual en junio de 2009, se atrevió por primera vez a cobrar a sus clientes por cada bolsa de plástico que se le entregaba. Si requería empacar en bolsas, debería asumir un costo adicional. Lamentablemente, siete meses después, y tras las críticas de los usuarios, tuvo que reversar la decisión y volver a regalar las bolsas por las compras realizadas, para evitar posible desbandada de clientes.

$\mathrm{Si}$ fuésemos conscientes de nuestra responsabilidad con el planeta, no tardaríamos en protestar contra aquellos depredadores industriales, entre los que destacan entre varios los productores de los mal llamados "plásticos desechables".

La mayoría, por no decir que todas las personas en el mundo, hemos usado los cubiertos, vasos y platos plásticos. Esta práctica cada vez más frecuente y que tiende a inundar los mercados, no sólo los dirigidos a los hogares, sino más grave aún, con presencia masiva en los restaurantes de comida rápida, hace que el plástico se convierta hoy en un instrumento irremplazable del diario vivir en la sociedad.

Afortunadamente el hombre está buscando soluciones. Recientemente se han desarrollado vasos, cubiertos y platos biodegradables, se descomponen en 180 días después de ser usadas, resistentes hasta $62^{\circ}$ centígrados y elaborados con un polímero de maíz desarrollado por Nature Works y una mezcla de $80 \%$ de fécula de papa y $20 \%$ de aceite vegetal.

También se han desarrollado platos hechos en un $100 \%$ de fibra de azúcar de caña, un subproducto derivado del proceso de refinación del azúcar. Estos son mucho más resistentes que cualquier plato plástico o de papel. 


\section{Las cifras}

Según una encuesta realizada en 2010 y aplicada por Datexco y el Centro Nacional de Consultoría en Bogotá, Cali, Medellín y Barranquilla, a empleados, trabajadores independientes, amas de casa y estudiantes, pertenecientes a todos los estratos sociales, arrojó los siguientes resultados:

- El 63\% de los colombianos considera que el gobierno es el único responsable de solucionar los problemas ambientales del país. Desconoce la importancia que tiene el cliente y consumidor en el avance o atraso de las mejores prácticas ambientales.

- El 37\% de los colombianos, realizaría acciones para preservar el medio ambiente, si lo enseñaran a hacerlo

- El 74\% de las personas compran productos pensando en su bienestar y el de su familia, el $67 \%$ pensando en la economía, y tan sólo el $49 \%$ se asegura de que lo que compran no atente contra el medio ambiente. La población es consciente que los individuos tienen claro que son los causantes del deterioro del medio ambiente, pero no se consideran parte de la solución.

- Tan sólo el 38\% de los colombianos relaciona el ahorro de recursos con la vida del planeta, es decir, que piensa que si ahorra recursos beneficia al planeta, y finalmente, tan sólo el 14\% considera que al ahorro de recursos lo beneficia a él mismo. Puede parecer una cifra pequeña, pero es un porcentaje que sin embargo, ya decidió cambiar y adoptar nuevos y mejores hábitos de vida.

\section{Recicle y consuma mejor}

Como consumidores y clientes, tenemos el derecho a conocer la información de las compañías que nos proveen, por tanto, podemos solicitar información sobre los procesos que utilizan para producir sus bienes y /o servicios. Se hace necesario indagar si la marca de determinado producto que nos interesa, representa un insumo elaborado en pro del medio ambiente, de la misma manera en que es importante confirmar que dicha organización está al día con sus responsabilidades laborales, salariales, de seguridad social y ambiental con el país.

\section{Conclusiones}

Las redes empresariales requieren de una mayor conciencia en el ámbito empresarial por parte de los líderes de empresa y el gobierno donde se involucre las teorías de orientación a la cadena de abastecimiento y a la orientación sostenible para la mejora del desempeño logístico y organizacional.

Requerimos de una mayor conciencia y sentido de pertenencia con nuestro planeta. Para ello, tenemos diversas opciones que nos permiten colaborar a disminuir la contaminación en el planeta, bien sea a través de una adecuada recolección y reciclaje de los materiales que para muchos no son sino simplemente basura. Permitir el uso de un material que ya fabricado es irreversible, es una manera de colaborar y aportar un grano de arena a la problemática futura.

Es necesario pensar en estrategias como el supraciclaje es el proceso de convertir materiales de desecho o productos en desuso en nuevos materiales o productos de mejor calidad o con un mayor valor medioambiental o el infraciclaje donde materiales como el aluminio o el plástico son procesados para elaborar otro producto.

Las redes devalor dentro de su configuración estratégica, táctica y operacional debe 
contemplar toda una cultura hacia procesos inmersos en máximas de logística verde e inversa, tal como lo considera el modelo Supply Chain Operation Reference en sus últimas versiones (Ntabe et al., 2015).

\section{REFERENCIAS}

Consumiami (2012). Formación y entretenimiento en el consumo responsable. Recuperado de: http://www.mercadodedinero. com.co/Consumo/consumiami-2012-formacion-y-entretenimiento-en-el-consumo-responsable.html

Hernández, M. (2009). Carrefour sustituye sus bolsas de plástico. El Mundo Recuperado de: http://www.elmundo. es/mundodinero/2009/o9/01/economia/1251800623.html

Nieto, E. (2010). Soy ECO colombiano, campaña para promover la conciencia ambiental del país. Gestión estratégica para las Organizaciones sociales. Recuperado de: http://www.gestrategica.org/templates/ noticias_detalle.php?id=250

Ntabe, E. N., LeBel, L., Munson, A. D., \& Santa-Eulalia, L. A. (2015). A systematic literature review of the supply chain operations reference (SCOR) model application with special attention to environmental issues. International Journal of Production Economics, 169, 310-332. https://doi. org/10.1016/j.ijpe.2015.08.008

Signori,Flint, G. (2015). Toward sustainable supply chain orientation (SSCO): mapping managerial perspectives. International Journal of Physical Distribution $\mathcal{E}$ Logistics Management, 45(6), 536-564.
Ntabe, E. N., LeBel, L., Munson, A. D., \& Santa-Eulalia, L. A. (2015). A systematic literature review of the supply chain operations reference (SCOR) model application with special attention to environmental issues. International Journal of Production Economics, 169, 310-332. https://doi. org/10.1016/j.ijpe.2015.08.008

Signori,Flint, G. (2015). Toward sustainable supply chain orientation (SSCO): mapping managerial perspectives. International Journal of Physical Distribution E Logistics Management, 45(6), 536-564. 